\title{
Cryptobenthic fish assemblages across the coral reef-seagrass continuum in SE Sulawesi, Indonesia
}

\author{
Gabby N. Ahmadia1,* Laura J. Sheard ${ }^{2}$, Frank L. Pezold ${ }^{1}$, David J. Smith ${ }^{3}$ \\ ${ }^{1}$ College of Science and Engineering, Texas A\&M University-Corpus Christi, 6300 Ocean Drive, Corpus Christi, Texas 78412, USA \\ ${ }^{2}$ School of Biology, University of St. Andrews, Bute Building, St Andrews, Fife KY16 9TS, UK \\ ${ }^{3}$ Coral Reef Research Unit, Department of Biological Sciences, University of Essex, Wivenhoe Park, Colchester CO4 3SQ, UK
}

\begin{abstract}
Cryptobenthic fishes have a significant influence on coral reef ecosystem dynamics; however, they have received considerably less attention than their larger, more conspicuous fish counterparts. In nearby seagrass zones, there is little or no information about cryptobenthic fishes, even for basic parameters such as density and distribution, although smaller organisms may have a substantial effect on ecosystem processes. The present study investigated cryptobenthic fish distribution and microhabitat use in the coral reef-seagrass continuum in SE Sulawesi, Indonesia. Cryptobenthic fishes were sampled from dominant microhabitats in 3 zones - reef flat, bommie, and seagrass beds. Abundance and diversity of cryptobenthic fishes within microhabitats of each zone were comparable. Consequently, they are likely an important food resource for predatory transient and resident fishes in the seagrass and bommie zones, and could influence ecosystem dynamics in a manner observed on coral reefs. In addition, there were no clear differences between fish microhabitat use and assemblage structure across zones. This suggests microhabitat availability is the key determinant of cryptobenthic fish distribution throughout the coral reefseagrass continuum, despite the changes in biological and physical conditions among the zones. Lastly, this research provides, for the first time, initial estimates of density and diversity of cryptobenthic fishes along the coral reef-seagrass gradient within the Coral Triangle.
\end{abstract}

KEY WORDS: Cryptobenthic fishes $\cdot$ Biodiversity $\cdot$ Coral reefs $\cdot$ Seagrass $\cdot$ Indonesia

\section{INTRODUCTION}

Coral reefs and seagrass beds are highly productive ecosystems providing habitat for diverse fish assemblages. When these ecosystems are located in close spatial proximity, the diversity and biomass of inhabiting fish populations often increase (Mumby et al. 2004, Dorenbosch et al. 2005a, Unsworth et al. 2008). Connectivity exists between these ecosystems in part because many reef fishes use seagrass beds as both nursery habitats and foraging grounds (Mumby et al. 2004, Dorenbosch et al. 2005b, Unsworth et al. 2008, 2009, Verweij et al. 2008). Studies on fish assemblages across these different zones have generally focused on larger, conspicuous reef fishes (Mum- by et al. 2004, Dorenbosch et al. 2005b, 2007, Unsworth et al. 2008), without consideration of the smaller, yet ecologically important cryptobenthic fishes (Ackerman \& Bellwood 2000, 2003, Depczynski \& Bellwood 2003). For a more comprehensive understanding of fish assemblage structure and habitat utilization in these different ecosystems, cryptobenthic fishes (Ackerman \& Bellwood 2000: adults normally $<50 \mathrm{~mm}$ in length and closely associated with the benthos) need to be included. Cryptobenthic fishes occur in high diversity in coral reef systems (Ackerman \& Bellwood 2003, Depczynski \& Bellwood 2003), yet little work has examined their assemblage structure along the continuum between the reef crest and seagrass beds. When studies have 
been extended to adjacent seagrass beds, they have been limited to a few targeted species (Hernaman \& Probert 2008).

The ecological importance of cryptobenthic fishes is largely based on their high density on coral reefs. They have been estimated to comprise as much as $50 \%$ of the abundance of fishes on coral reefs in the Great Barrier Reef (Ackerman \& Bellwood 2000, 2003). Though the biomass of these fishes is considerably lower than that of larger reef fishes, they are highly productive due to quick turnover rates and their fast metabolism (Ackerman \& Bellwood 2003, Depczynski et al. 2007). In addition, many cryptobenthic fishes are detritivores, providing an important link between primary production and higher trophic levels (Riddle et al. 1990, Depczynski \& Bellwood 2004). Together, their high densities, productivity, and trophic status suggest that they are a key functional group on coral reefs (Ackerman \& Bellwood 2003). Examining their distribution patterns in adjacent ecosystems will provide some indication of their ecological role beyond the coral reef.

Distribution of cryptobenthic fishes is linked to microhabitat availability, as the small-scale assemblage structure of coral reef cryptobenthic fishes is strongly related to the characteristics of the microhabitats present (Munday et al. 1997, Depczynski \& Bellwood 2004, Herler 2007). However, the strength of cryptobenthic fish-microhabitat associations has been shown to be influenced by properties of the physical environment such as wave action (Depczynski \& Bellwood 2005, Santin \& Willis 2007) and habitat degradation (Bellwood et al. 2006). The present study investigates other potential factors that may influence cryptobenthic fish microhabitat associations by examining assemblages in key microhabitats across the coral reef-seagrass continuum. Specifically, our study tested the null hypotheses that cryptobenthic fish density, diversity, and assemblage composition will not significantly change in microhabitats across the coral reef-seagrass continuum. Rejection of the hypotheses would indicate that cryptobenthic fishes exhibit changes in assemblage structure across the coral reef-seagrass continuum similar to patterns shown by larger fishes (Ospina \& Mora 2004, Unsworth et al. 2007b, Nilsson et al. 2009, 2010). Acceptance of the hypotheses would suggest cryptobenthic fishes maintain strong microhabitat associations throughout the coral reef-seagrass continuum despite biological and physical alterations associated with changes in zone. The present study also examined habitat partitioning of different species of cryptobenthic fishes. Many cryptobenthic fish species have specific microhabitat preferences (Munday et al. 1997, Depczynski \& Bellwood 2004, Herler 2007), though it is unclear to what extent habitat partitioning occurs. Although most research on cryptobenthic fish assemblages focuses on 3 or 4 primary microhabitat types (Depczynski \& Bellwood 2003, 2004, 2005), the present study distinguished 7 different microhabitat types. Further research investigating distribution patterns and factors structuring cryptobenthic fish assemblages will ultimately provide a better understanding of the ecological role of these fishes in tropical coastal ecosystems.

\section{MATERIALS AND METHODS}

\section{Site description}

Data collection was conducted during the months July through August 2009 at the Hoga Marine Research facility in the Wakatobi Marine National Park located within the Tukangbesi Archipelego, SE Sulawesi, Indonesia (Fig. 1). Sampling of microhabitats occurred within 3 distinct zones (reef flat, bommie, seagrass) on the inshore flats of the fringing sheltered reef west of Hoga Island $\left(5^{\circ} 28.40^{\prime} \mathrm{S}, 123^{\circ} 45.45^{\prime} \mathrm{E}\right)$ (Fig. 2), with a tidal maximum amplitude of $2.3 \mathrm{~m}$ (Unsworth et al. 2007b). The reef flat zone is composed primarily of continuous and patch reef, with rubble and sand areas composing the remaining substrate. The bommie zone consists of coral bommies with larger tracts of rubble and sand. The seagrass zone is located within the edge of the seagrass beds with even more isolated coral and rock bommies. Seagrass beds in this region are composed primarily of 2 species: Thalassia hempriichii and Enhalus acoroides.

There are physical and biological differences associated with each zone based on previous studies in the region. Predation levels differ between zones, with predation threat being more constant in the reef flat zone, and increasing variability of predation pressures moving inshore from the reef flat towards the seagrass zone due to the transient nature of many of the fish predators in the bommie and seagrass zones that migrate in and out of the reef as dictated by diel and tidal cycles (Unsworth et al. 2007b). Physical parameters are also increasingly more variable further inshore due to tides, as the shallow inshore waters experience greater changes in depth profile, in turn, causing more fluctuations in temperature and duration of exposure (Unsworth et al. $2007 \mathrm{a}, \mathrm{b})$. 


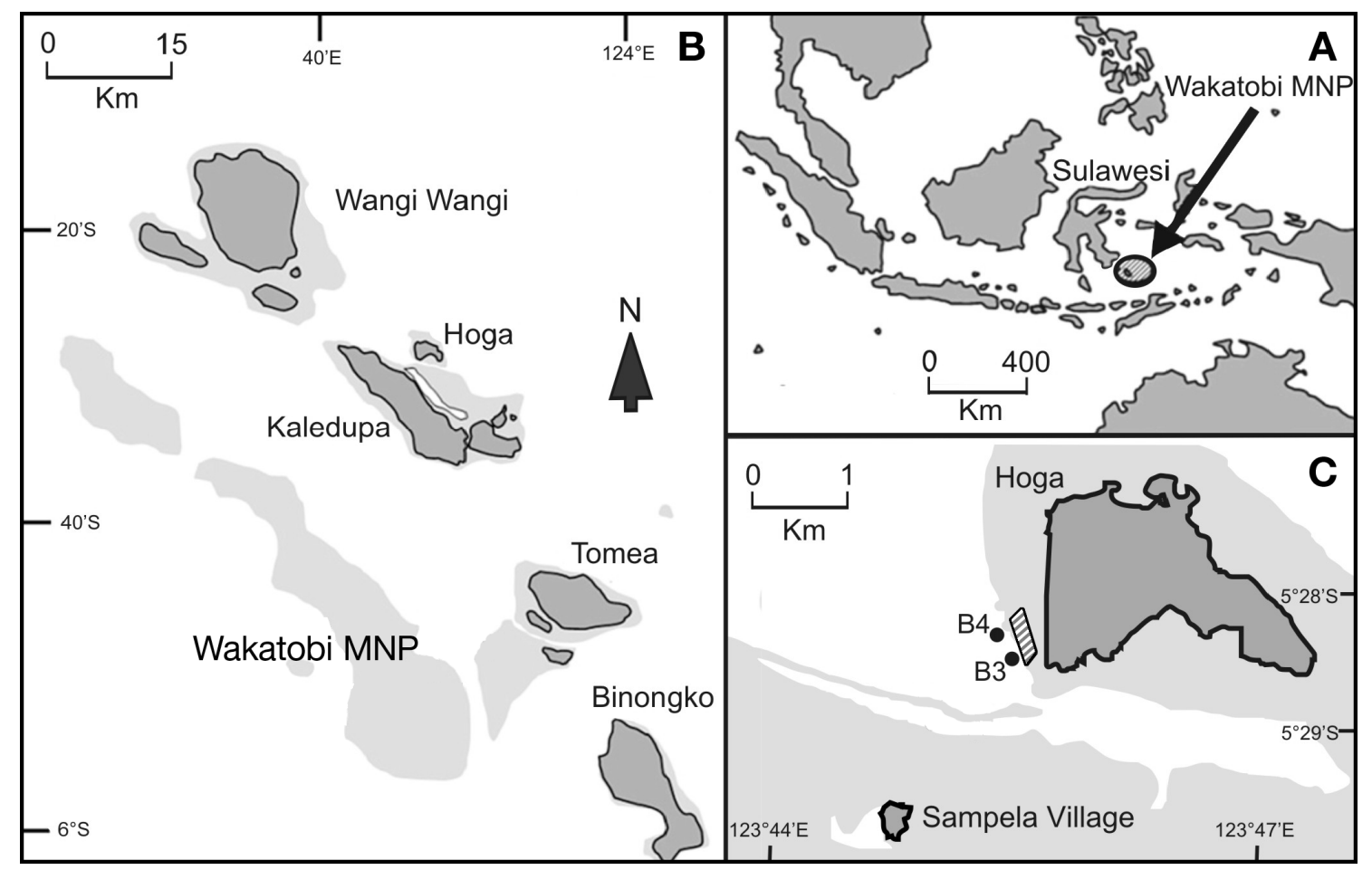

Fig. 1. Map of study site (modified from Unsworth et al. 2008). Study site is located in Indonesia (A), within the Wakatobi Marine National Park (MNP) (B), in the coral reefs and seagrass around Hoga Island (C). Dark gray shading: landmasses; light gray shading: intertidal areas extending to the reef crest; white: deep waters. The hatched area encompasses the 3 zones where sampling took place; B3 and B4: the mooring points used

\section{Collection methods and sampling design}

Cryptic fishes were collected from 7 dominant microhabitats replicated 5 to 7 times in each of the zones for a total of 98 samples (Table 1). Microhabitats were categorized as branching Porites, table coral, rubble, sand, soft coral, rock and sponge. For this particular study, the term sponge is used solely for the foliose sponge Phyllospongia. Rock bommies are categorized as hardened substrate or coral rock that is predominately bare, but also houses a diverse array of sessile invertebrates. Branching Porites was not sampled in the seagrass zone because it rarely occurred, and, when it did, it was very small in size. Phyllospongia was not sampled within the reef flat zone because it occurs in very low abundance. Though fairly common, rock was not sampled within the reef crest because it did not occur in patches large enough to provide a homogeneous sample within the sampling quadrat.

Sampling plots were haphazardly chosen using random compass bearings and swim kicks to get to a particular point within a zone, and then the closest targeted microhabitat type was selected. Each $0.36 \mathrm{~m}^{2}$ sampling area was enclosed by a $2.5 \times 0.5 \mathrm{~m}$

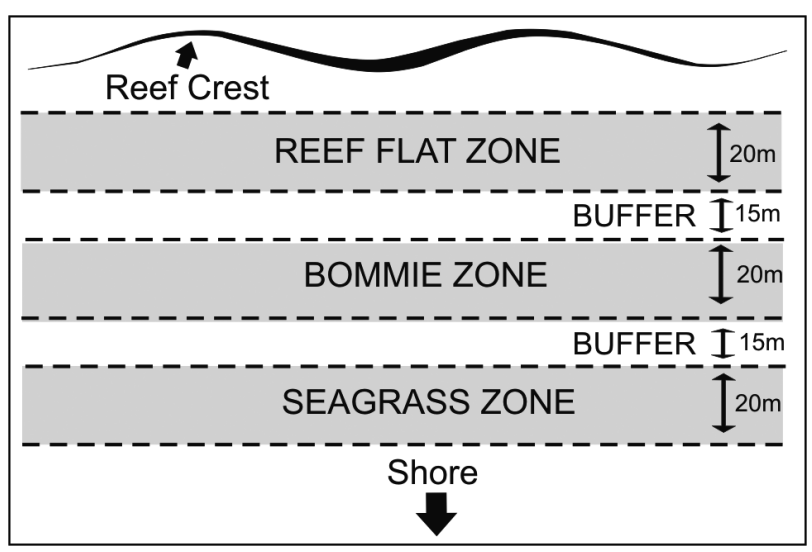

Fig. 2. Diagram of different zones where sampling occurred within the coral reef-seagrass continuum

fine-mesh net in-weighted on the bottom edge with a fine link chain. The area was then covered with a plastic sheet to enclose the fish anesthetic. Fishes were anesthetized with a $100 \mathrm{ml}$ mixture of 4 parts ethanol to 1 part clove oil dispersed within the sampling area using two $60 \mathrm{ml}$ syringes. The anesthetic remained in the sampling area for $1 \mathrm{~min}$, then the net and plastic sheet were carefully removed and fishes 
Table 1. Experimental design showing number of cryptobenthic fish samples from each microhabitat and zone. Dashes: no sampling took place within the microhabitat and zone

\begin{tabular}{|lcccc|}
\hline Microhabitat & Reef flat & Bommie & Seagrass & Total \\
\hline Porites & 9 & 7 & - & 16 \\
Rock & - & 5 & 4 & 9 \\
Rubble & 5 & 6 & 5 & 16 \\
Sand & 5 & 5 & 5 & 15 \\
Soft coral & 6 & 6 & 6 & 18 \\
Sponge & - & 5 & 5 & 10 \\
Table coral & 5 & 4 & 5 & 14 \\
Total & 30 & 38 & 30 & 98 \\
\hline
\end{tabular}

were collected for a 10 min period. Fish specimens were then placed in an ice slurry to preserve coloration for photographs needed for taxonomic identification. Clove oil was selected as a fish anesthetic for regulation purposes as it is not as toxic as other methods; however, it may create some bias against crevice dwellers, as fish will become anesthetized within the burrow or hole, making them difficult to find at times.

Benthic cover in each zone was assessed by photographing 12 randomly placed $1 \mathrm{~m}^{2}$ square quadrats along 3 transects separated by $5 \mathrm{~m}$, all parallel to the reef crest. Images were analyzed using Coral Point Count (Kohler \& Gill 2006) by overlaying 50 random points on each image and identifying the substratum under each point. Categories of the substratum recorded included microhabitats selected for sampling of cryptobenthic fishes and were categorized as table corals, branching Porites, other hard coral, soft coral, rubble, sand, and rock.

\section{Statistical analyses}

Although the present study is limited to 3 different zones within 1 location, microhabitats were treated as individual replicates within each zone because of the high site fidelity and restricted spatial scale on which cryptobenthic fishes operate (Luckhurst \& Luckhurst 1978, Depczynski \& Bellwood 2004). This does limit interpretation, as the likelihood of unmeasured site-to-site variability is high, but it does provide a baseline comparison for future studies examining cryptobenthic fishes across the coral reefseagrass gradient.

Benthic data were recorded as percent cover and transformed using arcsine transformations (typically used for percentages). Data were heteroscedastic and deviated from a normal distribution, therefore a 1-way permutational multivariate ANOVA (PERM-
ANOVA); (Euclidean distance, unrestricted permutation of raw data) using the software PRIMER (Clarke \& Gorley 2006) was used to compare benthic composition across zones. PERMANOVA is an alternative to an ANOVA that does not rely on the assumption of normality.

Both density and diversity data were transformed with multiple methods; however, again, data were heteroscedastic and deviated from a normal distribution. Subsequently, 2-way PERMANOVAs (Euclidean distance; permutation of residuals under a reduced model) were used to compare fish density and diversity between zones (random) and microhabitats (fixed). Significant factors were followed by PERMANOVA pairwise comparison tests. Diversity for fish assemblages within each microhabitat sampled was measured using the Hill index (N1; Hill 1973), which is calculated using the following equation:

$$
\mathrm{N} 1=e^{H^{\prime}}
$$

where $H^{\prime}$ is Shannon's index:

$$
H^{\prime}=-\sum_{i=1}^{s}\left(p_{i,} \ln \left(p_{\mathrm{i},}\right)\right)
$$

in which $p_{i}$ is the proportion of species $i$ in the sample and $s$ is the number of species. N1 is sensitive to rare species and is thus appropriate for the study. A 2-way PERMANOVA (Bray-Curtis similarity; permutation of residuals under a reduced model) was used to compare species assemblage composition between zone (random) and microhabitats (fixed). For the PERMANOVA analyses, density and assemblage data were transformed using fourth root transformations (PRIMER), whereas no transformations were applied to the diversity data. Fourth root transformations were used as they are considered an intermediate transformation without giving too much weight to either exceptionally high or low values. All statistical significance was based on $\alpha=0.05$.

Non-metric multidimensional plots (nMDS, fourth root transformation, Bray-Curtis similarity), also conucted in PRIMER, were used to examine the similarity among cryptobenthic fish assemblages on each of the microhabitat types. Spearman correlations were carried out to determine the magnitude of individual species contribution to the characterization of clusters in space. Clusters from the BrayCurtis analysis were also superimposed on the MDS ordination plots.

A cluster analysis (Wards) was also performed on the 17 most abundant species (occurred $>6$ times) and their microhabitat use. Data were fourth-root transformed, and Bray-Curtis similarity was perfor- 
med on the variable species (as opposed to samples). This was conducted to determine species affiliations for particular microhabitats. Microhabitats were mapped onto the cluster diagram according to relative occurrence of species on microhabitats (if they occurred $>70 \%$ of the time in the microhabitat).

\section{RESULTS}

\section{Benthic cover}

As expected, analyses of benthic composition revealed clear distinctions between the zones for microhabitat attributes (1-way PERMANOVA, pseudo $F_{2,7}=5.77, \mathrm{p}_{\text {perm }}=0.018$ ). The more structurally complex microhabitat types (i.e. rocks, branching corals) decreased in density further inshore, replaced largely by sand and seagrass (Fig. 3). Essentially, the further the zone is inshore, the more fragmented the structurally complex habitat.

\section{Cryptobenthic fishes}

A total of 548 cryptobenthic fishes were collected from the different microhabitat types and zones, representing 52 species from 14 different families (Appendix 1). The greatest number of species was found in the bommie zone (38 fish species), followed by the

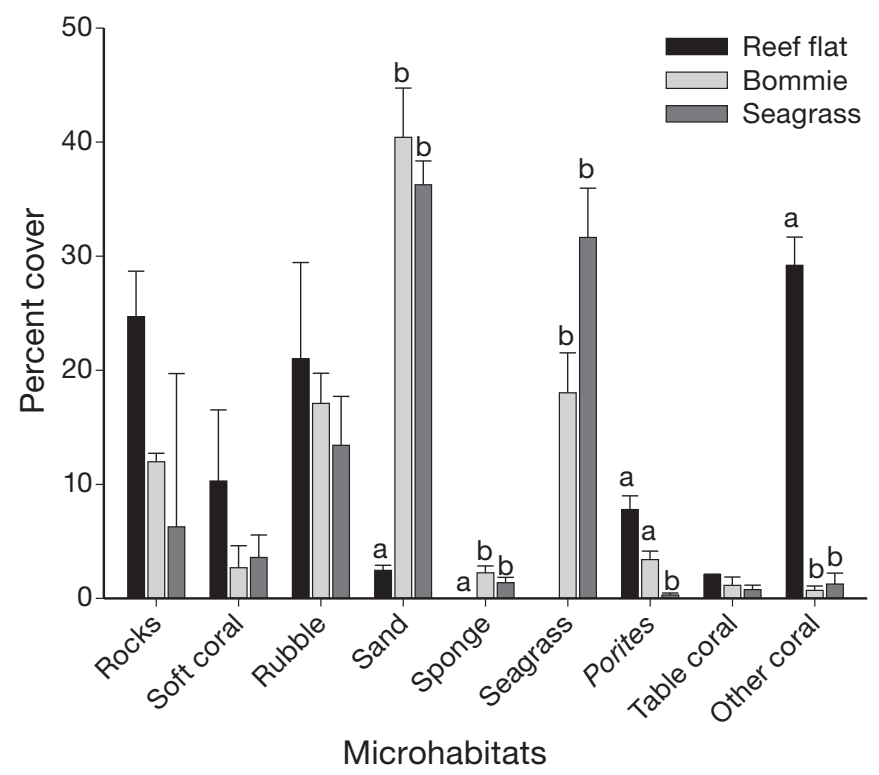

Fig. 3. Mean percent cover $( \pm \mathrm{SE})$ of microhabitats along transects in 3 shallow-water zones extending from the reef crest to seagrass. Different lowercase letters above bars indicate significant differences across zones seagrass zone (32 fish species), with the fewest species (29) observed in the reef flat zone. Gobiidae was by far the most abundant family ( $84 \%$ of fishes collected) and the most diverse (64\% of species observed). It was also the only family observed in all microhabitat types in all zones (Appendix 1).

\section{Cryptobenthic fish density and diversity}

Fish density was highly variable within microhabitats and zones (Fig. 4). Fish density was significantly different among microhabitats, but not zones (microhabitat: PERMANOVA, $F_{6,97}=4.0775, \mathrm{p}_{\text {perm }}=0.013$; zone: PERMANOVA, $\mathrm{F}_{2,97}=2.2408, \mathrm{p}_{\text {perm }}=0.104$; microhabitat $\times$ zone: PERMANOVA, $F_{9,97}=1.2318$, $\mathrm{p}_{\text {perm }}=0.268$ ). Follow-up pairwise PERMANOVA multiple comparisons were conducted between microhabitats across all zones, though no significant differences were found between any of the micro-
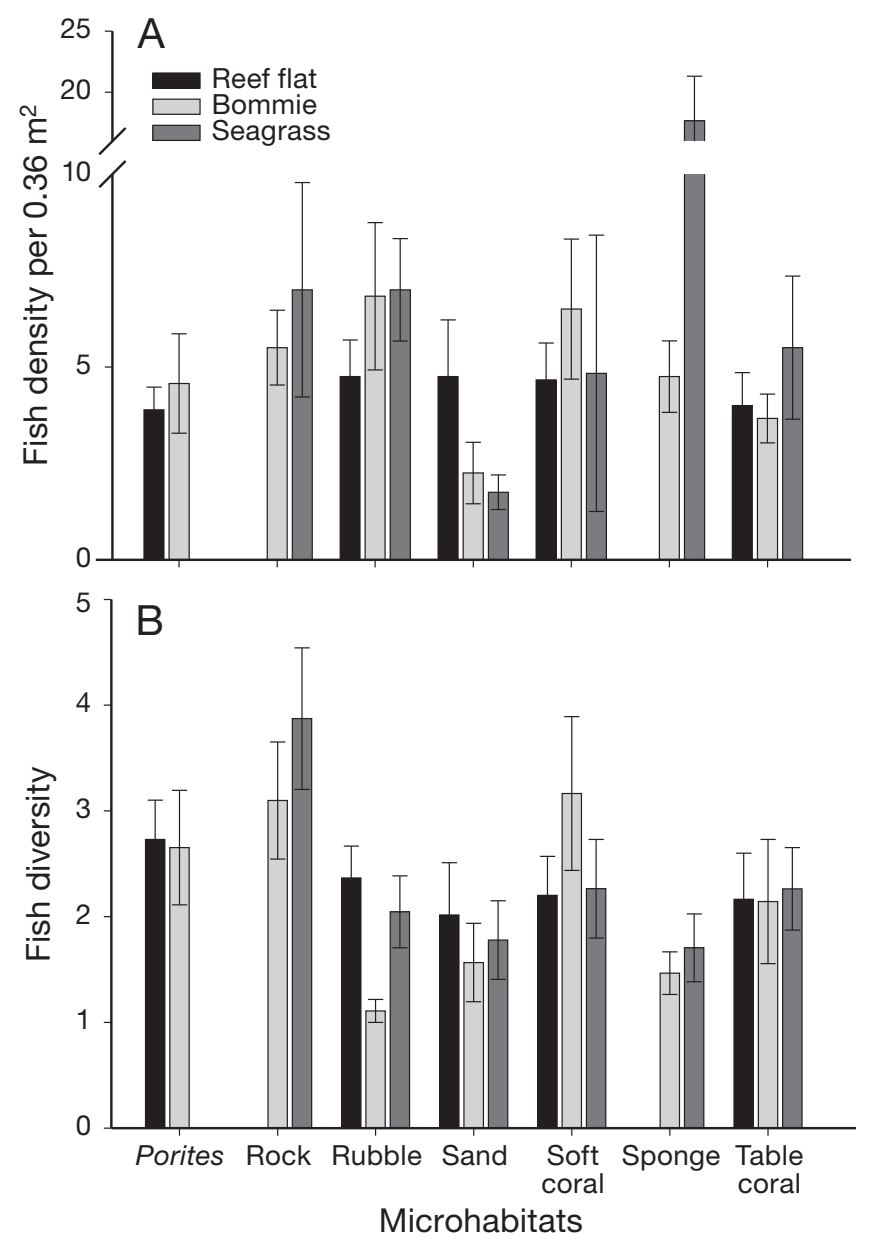

Fig. 4. Mean $( \pm \mathrm{SE})$ of (A) cryptobenthic fish density per $0.36 \mathrm{~m}^{2}$ and (B) fish diversity according to Hill's index (N1), in different microhabitats in 3 zones $(n=98)$ 
habitat types. Similar to fish density, species diversity differed significantly among microhabitats, but not zone (microhabitat: PERMANOVA, $F_{6,97}=1.103$, $\mathrm{p}_{\text {perm }}=0.044 ;$ zone: PERMANOVA, $F_{2,97}=3.4326$, $\mathrm{p}_{\text {perm }}=0.044$; microhabitat $\times$ zone: PERMANOVA, $F_{9,97}=0.9175, p_{\text {perm }}=0.607$ ). Again, follow-up pairwise PERMANOVA multiple comparisons did not indicate any significant differences between specific microhabitat types.

\section{Cryptobenthic fish assemblage structure}

PERMANOVA analysis was used to assess the significance of differences in species assemblage composition among microhabitats and zones. Cryptobenthic fish assemblage structure varied significantly among microhabitats (PERMANOVA, $F_{6,97}=8.245$, $\left.\mathrm{p}_{\text {perm }}=0.001\right)$ and zones (PERMANOVA, $F_{2,97}=$ $1.7682, p_{\text {perm }}=0.047$ ); however, there was significant interaction between microhabitat and zone (PERMANOVA, $\left.F_{9,97}=1.597, p_{\text {perm }}=0.009\right)$. Thus, pairwise PERMANOVA multiple comparisons were used to compare microhabitats within and between zones for the term zone $\times$ microhabitat. Significant differences occurred between fish assemblages in almost every microhabitat comparison within each zone $(\alpha<$ 0.05). The exceptions were in the reef flat zone, in which fish assemblages in rubble did not significantly differ from sand or soft coral, and the seagrass zone, in which rock fish assemblages were not significantly different from either rubble or soft coral fish assemblages $(\alpha<0.05)$. All assemblages on microhabitats were significantly different from one another in the bommie zone $(\alpha<0.05)$. Pairwise tests comparing individual microhabitats between zones indicated no significant differences occurred for fish assemblages found on rock or soft coral $(\alpha<0.05)$. Significant differences did occur between the reef flat and bommie zone for fish assemblages on rubble and between the reef flat and seagrass zones for fish assemblages on table coral and sand $(\alpha<0.05)$.

Cryptobenthic fish assemblages were more closely related between microhabitats than between zones. This is illustrated by the ordination analysis which allows for a visual representation of the differences/ similarities among fish assemblages associated with different microhabitat types (Fig. 5A,B), while the vector overlay shows the fish species most responsible for driving the differences. Species assemblages in sponge, table coral, and sand microhabitats formed defined clusters, indicating unique assemblages occurred in those microhabitats. Fish assem- blages in rubble, soft coral, branching Porites, and rock were all most closely related and characterized by a strong presence of the species Eviota queenslandica. An nMDS plot restricted to this cluster (Fig. 5B) indicated that fish assemblages were distinctive between microhabitat types.

\section{Habitat partitioning}

Many of the fish species showed strong associations with particular microhabitat types (Fig. 6), indicating some level of habitat specialization. The 'indeterminate' group was comprised of species with
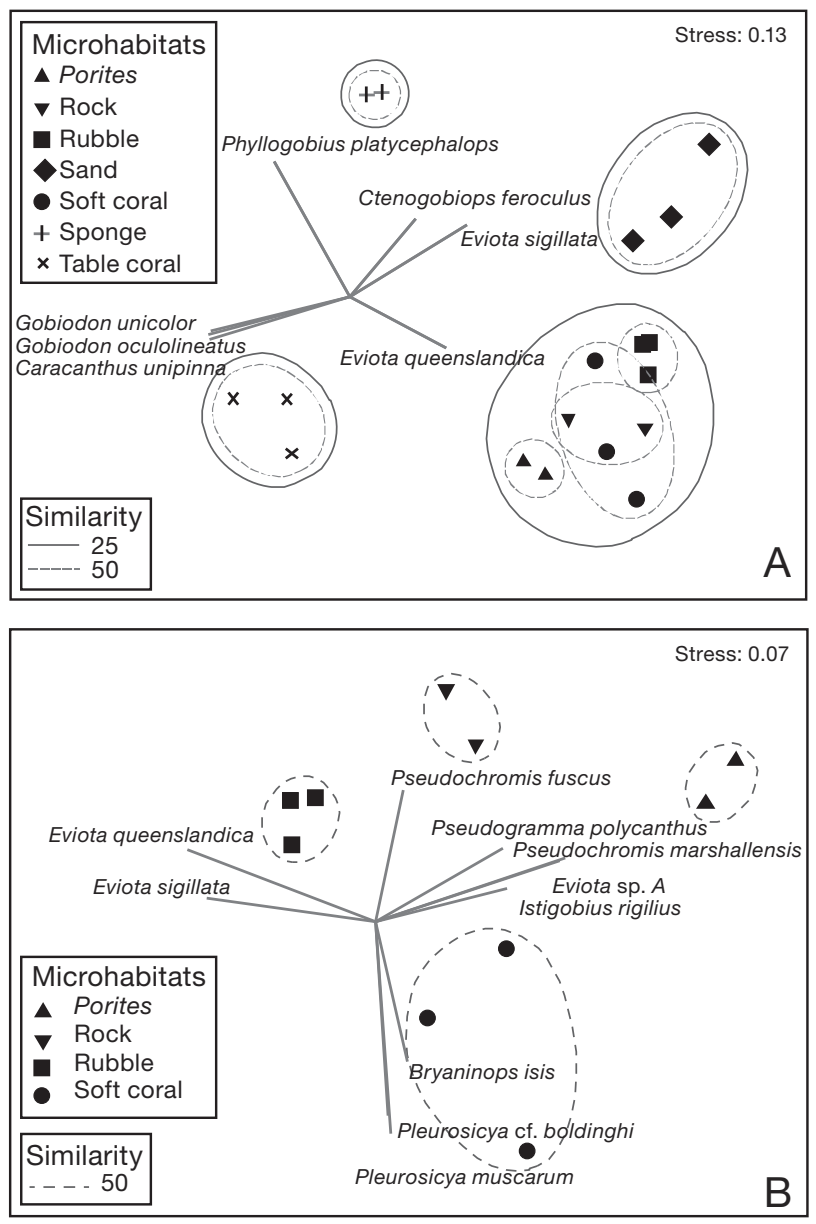

Fig. 5. (A) Non-metric multidimensional scaling ordination plot of cryptobenthic fish communities' most abundant fish species (>3 per microhabitat type), with Spearman's correlation vectors superimposed on the plot (vector lengths restricted to $>0.40$ ). Each symbol is representative of all cryptic fishes sampled among the microhabitats within a zone. Circle outlines encompass groups of differing similarity. (B) As in (A) but based on a subset of initial plots in order to provide finer resolution 


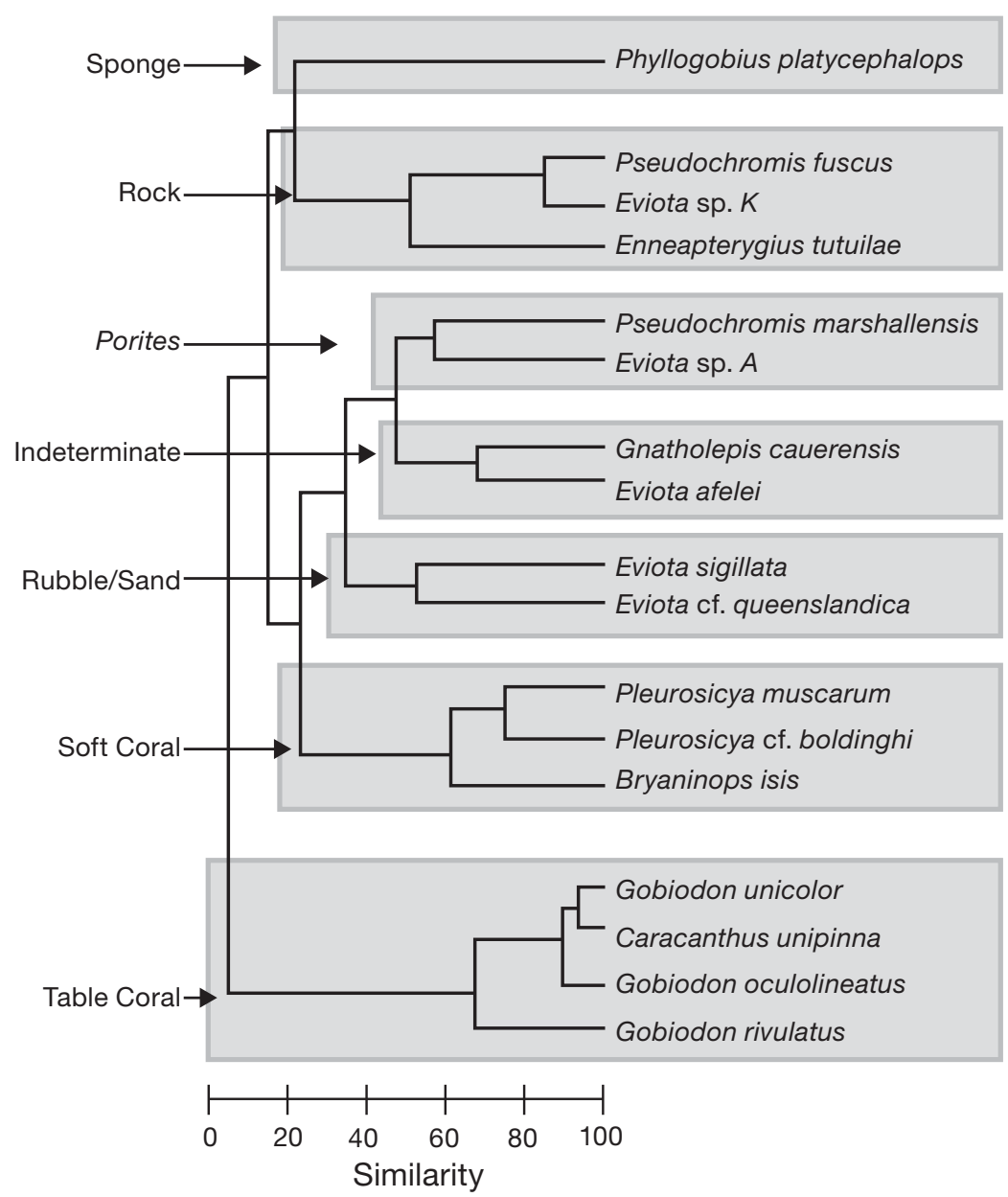

Fig. 6. Cluster analysis (Bray-Curtis similarity, Wards' method) of the most abundant cryptobenthic species ( $>5$ per microhabitat type) based on their microhabitat use. The degree of similarity between species microhabitat use is indicated on the scale across the bottom. Microhabitat groups were assigned based on their relative occurrence on the microhabitat $(>70 \%)$. Indeterminate grouping was assigned for those species that did not occur predominately in one microhabitat

preferences for 2 or more microhabitats and could be considered to be habitat generalists. Many species within a genus had similar microhabitat preferences, for example, fishes within the genus Gobiodon were associated with table coral and fishes within the genus Pleurosicya were associated with soft coral. This was not always the case, as species of Eviota had different microhabitat associations.

\section{DISCUSSION}

The present study provided the first quantitative assessment of cryptobenthic fish distribution patterns from the coral reef to the seagrass beds. Species richness of cryptobenthic fishes in a coral reef-seagrass continuum was similar to species richness of larger fishes observed in visual surveys recorded previously at the same location (Unsworth et al. 2007a). Fifty-two cryptobenthic fishes were found across these zones, compared to approximately 59 fish species that were recorded in the visual survey (Unsworth et al. 2007a). Assuming the visual surveys did not incorporate cryptobenthic fishes (of the top 30 species reported no cryptic species were listed), this indicates an estimated $47 \%$ of all fish species were not included. Cryptobenthic fish density was also substantially higher compared to the visual surveys of larger fishes at the same location (Unsworth et al. 2007a). Based on the data of larger fishes, the highest density observed in a habitat (corals) is about 1 fish $\mathrm{m}^{-2}$, while the lowest cryptobenthic density observed in the present study in a habitat (sand) is approximately 5 fish $\mathrm{m}^{-2}$. This further demonstrates that cryptobenthic fishes are typically underrepresented, not just in the coral reef (Ackerman \& Bellwood 2000), but also in adjacent ecosystems. Ideally, multiple field techniques such as the use of a fish anesthetic in combination with visual surveys should be used in reef censuses for a more accurate representation of the overall fish assemblages.

Density and diversity of cryptobenthic fish assemblages within microhabitats were fairly similar across the coral reef-seagrass continuum. Although differing biological and physical factors across zones have been identified previously as having significant effects on the density and diversity of larger, more conspicuous reef fishes (Ospina \& Mora 2004, Unsworth et al. 2007b, Nilsson et al. 2009, 2010), the effects appear to be minimal on the distribution of cryptobenthic fishes in various microhabitats throughout the zones. It appears that cryptobenthic fishes are able to exploit microhabitats in a wide range of environmental conditions, and are much more ubiquitous across these microhabitats than other larger reef fishes.

Shifts were detected in cryptobenthic fish assemblage structure across the coral reef-seagrass gradient, though this was not observed for assemblages in 
every microhabitat type. This shift in cryptobenthic fish assemblage structure was more subtle than for larger fishes across these different zones which often showed marked differences between zones (Dorenbosch et al. 2005b, Unsworth et al. 2007a). In addition, cryptobenthic fish assemblages were much more similar within a microhabitat type than within a zone. Essentially, microhabitat characteristics appear to be the driving factor structuring cryptobenthic fish assemblages, with changes in zone across the coral reef-seagrass continuum taking a secondary role. If their preferred microhabitat occurs, individuals appear to occupy the microhabitat despite differences in physical and biological conditions between zones.

Although the emphasis of the study was not to examine differences between cryptobenthic fish assemblages in different microhabitats, as this has already been well described (Depczynski \& Bellwood 2004, Herler 2007), results do further substantiate the strength of microhabitat associations of cryptobenthic fishes (Depczynski \& Bellwood 2004, Herler 2007). Almost every microhabitat type housed unique cryptobenthic fish species assemblages. Differences were also found in cryptobenthic fish diversity and density among microhabitats; however, for both metrics, follow-up multiple comparisons did not indicate any significant differences between particular microhabitat types. This may be a limitation of sample size and the variability in the data.

\section{Habitat partitioning}

The degree of habitat partitioning exhibited by many cryptobenthic fishes appears to exceed that reported for most other reef fishes (Bean et al. 2002, Zekeria et al. 2002). Some of these patterns were expected owing to obligate habitat associations of soft coral-dwelling species within the genera Pleurosicya and Bryaninops (Munday et al. 1997, Depczynski \& Bellwood 2004, Herler 2007), the table coral-dwelling goby species within the genus Gobiodon (Munday et al. 1997, Depczynski \& Bellwood 2004, Herler 2007), and the Phyllogobius gobies that have a commensal relationship with foliose sponges (Randall 1997). The species-rich genus Eviota is of particular interest because it was found in a diversity of microhabitat types, and yet there were several examples of speciesspecific microhabitat associations. Eviota species occupy many different niches on the coral reef linked to the success of this group. This large genus currently has approximately 80 described species (Froese 2011) and many more likely undescribed.
Many cryptobenthic fishes appear to be habitat specialists, facilitating coexistence of numerous cryptobenthic fishes in these ecosystems. In theory, greater habitat partitioning reduces competitive interactions (Levins \& Culver 1971, Bonsall et al. 2002). The trade-off is that habitat specialists may be more sensitive to environmental disturbances compared to habitat generalists. Nonetheless, cryptobenthic fishes were present in microhabitats in all zones of the environmental gradient surveyed in the current study, and thus appear to be more responsive to changes in microhabitat availability than other environmental factors.

\section{SUMMARY}

Results of the present study indicate that microhabitat availability is the principal determinant of cryptobenthic fish abundance and species distributions in a coral reef-seagrass gradient that encompasses a wide range of biological and physical conditions. This suggests that there is some level of predictability in cryptobenthic fish assemblages, assuming there is information available on the benthic composition of an area. Abundance and diversity of cryptobenthic fishes within microhabitats of the bommie and seagrass zones were comparable to those of the reef flat. Consequently, cryptobenthic fishes are likely an important food resource for predatory transient and resident fishes, and could potentially influence ecosystem dynamics in a manner observed on other coral reefs (Ackerman \& Bellwood 2003, Depczynski \& Bellwood 2003, Depczynski et al. 2007). This research also revealed that cryptobenthic fishes partition habitats on a finer spatial scale than what has previously been documented, indicating that high degrees of habitat specialization are characteristic of many cryptobenthic species. Lastly, this research provides, for the first time, estimates of density and diversity of cryptobenthic fishes along the coral reef-seagrass gradient within the Coral Triangle (Allen 2008, Briggs 2009).

\section{LITERATURE CITED}

Ackerman JL, Bellwood DR (2000) Reef fish assemblages: a re-evaluation using enclosed rotenone stations. Mar Ecol Prog Ser 206:227-237

Ackerman JL, Bellwood DR (2003) The contribution of small individuals to density-body size relationships. Oecologia 136:137-140

Allen GR (2008) Conservation hotspots of biodiversity and endemism for Indo-Pacific coral reef fishes. Aquat 
Conserv 18:541-556

Bean K, Jones GP, Caley MJ (2002) Relationships among distribution, abundance and microhabitat specialisation in a guild of coral reef triggerfish (family Balistidae). Mar Ecol Prog Ser 233:263-272

Bellwood DR, Hoey AS, Ackerman JL, Depczynski M (2006) Coral bleaching, reef fish community phase shifts and the resilience of coral reefs. Glob Change Biol 12: 1587-1594

Bonsall MB, Hassell MP, Asefa G (2002) Ecological tradeoffs, resource partitioning, and coexistence in a hostparasitoid assemblage. Ecology 83:925-934

Briggs JC (2009) Diversity, endemism and evolution in the Coral Triangle. J Biogeogr 36:2009-2010

Clarke KR, Gorley RN (2006) Primer v6: user manual/tutorial. PRIMER, Plymouth

> Depczynski M, Bellwood DR (2003) The role of cryptobenthic reef fishes in coral reef trophodynamics. Mar Ecol Prog Ser 256:183-191

> Depczynski M, Bellwood DR (2004) Microhabitat utilisation patterns in cryptobenthic coral reef fish communities. Mar Biol 145:455-463

> Depczynski M, Bellwood DR (2005) Wave energy and spatial variability in community structure of small cryptic coral reef fishes. Mar Ecol Prog Ser 303:283-293

> Depczynski M, Fulton CJ, Marnane MJ, Bellwood DR (2007) Life history patterns shape energy allocation among fishes on coral reefs. Oecologia 153:111-120

Dorenbosch M, Grol MGG, Christianen MJA, Nagelkerken I, van der Velde G (2005a) Indo-Pacific seagrass beds and mangroves contribute to fish density coral and diversity on adjacent reefs. Mar Ecol Prog Ser 302:63-76

> Dorenbosch M, Grol MGG, Nagelkerken I, van der Velde G (2005b) Distribution of coral reef fishes along a coral reef-seagrass gradient: edge effects and habitat segregation. Mar Ecol Prog Ser 299:277-288

> Dorenbosch M, Verberk W, Nagelkerken I, van der Veldel G (2007) Influence of habitat configuration on connectivity between fish assemblages of Caribbean seagrass beds, mangroves and coral reefs. Mar Ecol Prog Ser 334: 103-116

Froese TaDP (2011) FishBase, Version 8/2011. www.fishbase.org

Herler J (2007) Microhabitats and ecomorphology of coraland coral rock-associated gobiid fish (Teleostei: Gobiidae) in the northern Red Sea. Mar Ecol 28:82-94

Hernaman V, Probert PK (2008) Spatial and temporal patterns of abundance of coral reef gobies (Teleostei: Gobiidae). J Fish Biol 72:1589-1606

Hill MO (1973) Diversity and evenness: a unifying notation and its consequences. Ecology 54:427-431

Kohler KE, Gill SM (2006) Coral Point Count with Excel extensions (CPCe): a Visual Basic program for the determination of coral and substrate coverage using random point count methodology. Comput Geosci 32:
1259-1269

Levins R, Culver D (1971) Regional coexistence of species and competition between rare species. Proc Nat Acad Sci 68:1246-1248

> Luckhurst BE, Luckhurst K (1978) Analysis of influence of substrate variables on coral-reef fish communities. Mar Biol 49:317-323

> Mumby PJ, Edwards AJ, Arias-Gonzalez JE, Lindeman KC and others (2004) Mangroves enhance the biomass of coral reef fish communities in the Caribbean. Nature 427:533-536

> Munday PL, Jones GP, Caley MJ (1997) Habitat specialisation and the distribution and abundance of coraldwelling gobies. Mar Ecol Prog Ser 152:227-239

> Nilsson GE, Crawley N, Lunde IG, Munday PL (2009) Elevated temperature reduces the respiratory scope of coral reef fishes. Glob Change Biol 15:1405-1412

Nilsson GE, Ostlund-Nilsson S, Munday PL (2010) Effects of elevated temperature on coral reef fishes: loss of hypoxia tolerance and inability to acclimate. Comp Biochem Physiol A 156:389-393

> Ospina AF, Mora C (2004) Effect of body size on reef fish tolerance to extreme low and high temperatures. Environ Biol Fishes 70:339-343

Santin S, Willis TJ (2007) Direct versus indirect effects of wave exposure as a structuring force on temperate cryptobenthic fish assemblages. Mar Biol 151:1683-1694

Randall JE, Allen GR, Steene RC (1997) Fishes of the Great Barrier Reef and Coral Sea. Crawford House Publishing Pty Ltd., Bathurst, NSW

Riddle MJ, Alongi DM, Dayton PK, Hansen JA, Klumpp DW (1990) Detrital pathways in a coral-reef lagoon. 1. Macrofaunal biomass and estimates of production. Mar Biol 104:109-118

> Unsworth RKF, Bell JJ, Smith DJ (2007a) Tidal fish connectivity of reef and sea grass habitats in the Indo-Pacific. J Mar Biol Assoc UK 87:1287-1296

> Unsworth RKF, Wylie E, Smith DJ, Bell JJ (2007b) Diel trophic structuring of seagrass bed fish assemblages in the Wakatobi Marine National Park, Indonesia. Estuar Coast Shelf Sci 72:81-88

Unsworth RKF, De Leon PS, Garrard SL, Jompa J, Smith DJ, Bell JJ (2008) High connectivity of Indo-Pacific seagrass fish assemblages with mangrove and coral reef habitats. Mar Ecol Prog Ser 353:213-224

- Unsworth RKF, Garrard SL, De Leon PS, Cullen LC, Smith DJ, Sloman KA, Bell JJ (2009) Structuring of Indo-Pacific fish assemblages along the mangrove-seagrass continuum. Aquat Biol 5:85-95

Verweij MC, Nagelkerken I, Hans I, Ruseler SM, Mason PRD (2008) Seagrass nurseries contribute to coral reef fish populations. Limnol Oceanogr 53:1540-1547

> Zekeria ZA, Dawit Y, Ghebremedhin S, Naser M, Videler JJ (2002) Resource partitioning among four butterflyfish species in the Red Sea. Mar Freshw Res 53:163-168 
Appendix 1. Number of individuals of cryptobenthic fish species collected from 7 different microhabitat types in 3 zones. Por: Porites; Rck: rock; Rub: rubble; Snd: sand; Sft: soft coral; Tbl: table coral; Spg: Sponge

\begin{tabular}{|c|c|c|c|c|c|c|c|c|c|c|c|c|c|c|c|c|c|c|c|}
\hline \multirow{2}{*}{$\begin{array}{l}\text { Family } \\
\text { Species }\end{array}$} & \multicolumn{5}{|c|}{- Reef flat -} & \multicolumn{7}{|c|}{$\longrightarrow$ Bommie } & \multicolumn{6}{|c|}{$\longrightarrow$ Seagrass } & \multirow[t]{2}{*}{ Total } \\
\hline & Por & Rck & Snd & Sft & Tbl & Por & Rck & Rub & Snd & Sft & Spg & $\mathrm{Tbl}$ & Rck & Rub & Snd & Sft & Spg & Tbl & \\
\hline Antennariidae & 1 & & & & & & & & & & & & & & & & & & 1 \\
\hline Atennariidae sp. & 1 & & & & & & & & & & & & & & & & & & 1 \\
\hline Bleniidae & 2 & & & & & & 2 & & & 2 & & & 3 & 1 & & & & & 10 \\
\hline Atrosalarias fuscus & 2 & & & & & & & & & & & & & & & & & & 2 \\
\hline Enneapterygius tutuilae & & & & & & & & & & & & & 1 & & & & & & 1 \\
\hline Escenius bimaculatus & & & & & & & & & & 1 & & & & & & & & & 1 \\
\hline Escenius trilineatus & & & & & & & & & & 1 & & & & & & & & & 1 \\
\hline Salarias fasciatus & & & & & & & & & & & & & & 1 & & & & & 1 \\
\hline Salarias guttata & & & & & & & 2 & & & & & & 2 & & & & & & 4 \\
\hline Caracanthidae & & & & & 7 & & & & & & & 2 & & & & & & 12 & 21 \\
\hline Caracanthus unipinna & & & & & 7 & & & & & & & 2 & & & & & & 12 & 21 \\
\hline Eleotridae & & 3 & & & & & & & & & & & & & & & & & 3 \\
\hline Calumia godeffroyi & & 3 & & & & & & & & & & & & & & & & & 3 \\
\hline Gobiesocidae & & & & & & 2 & & & & & & & & & & & & & 2 \\
\hline Lepadichthys sp. A & & & & & & 2 & & & & & & & & & & & & & 2 \\
\hline Gobiidae & 24 & 34 & 20 & 34 & 14 & 23 & 18 & 27 & 11 & 26 & 56 & 10 & 18 & 30 & 10 & 26 & 64 & 15 & 460 \\
\hline Amblygobius phalaena & & & & & & & & & & & & & & & & 2 & & & 2 \\
\hline Asterropteryx semipunctutatus & & & & & & & & & & & & & & 1 & & & & & 1 \\
\hline Bryaninops erythrops & 1 & & & & & 1 & & & & & & & & & & & & & 2 \\
\hline Bryaninops isis & & & & & & & & & & 6 & & & & & & 4 & & & 10 \\
\hline Cabillus tongarevae & & & & 1 & & & & & & & & & & & 2 & & & & 3 \\
\hline Callogobius hasseltii & & 1 & & & & 1 & & & & & & & 2 & & & & & & 4 \\
\hline Ctenogobius feroculus & & & & & & & & & 4 & & & & & & 2 & & & & 6 \\
\hline Eviota afelei & 4 & 1 & & 4 & & & & & & 2 & & & & & & & & & 11 \\
\hline Eviota albolineata & & & & 1 & & & & & & & & & & & & & & & 1 \\
\hline Eviota queenslandica & 6 & 19 & 2 & 8 & & 5 & 12 & 25 & 2 & 10 & 3 & 1 & 10 & 21 & & 5 & 1 & 1 & 118 \\
\hline Eviota infulata & 2 & & & & & & & & & & & & 1 & 1 & & & & & 4 \\
\hline Eviota sigillata & & 6 & 6 & 3 & 1 & & 1 & 2 & 4 & & & & 1 & 6 & 6 & & & & 36 \\
\hline Eviota sp. A & 9 & & & 1 & 2 & 13 & 2 & & & 1 & & 1 & & & & & & 1 & 30 \\
\hline Eviota sp. K & & & & & & & 2 & & & & & & 3 & & & & 2 & & 7 \\
\hline Fusigobius neophytus & & 1 & 1 & 1 & & & & & & & & & & & & & 1 & & 4 \\
\hline Gnatholepis cauerensis & 1 & 6 & 7 & 6 & & & & & & 3 & & & & & & & 4 & & 27 \\
\hline Gobiidae sp. A & & & 1 & & & & & & 1 & & & & & 1 & & & & & 3 \\
\hline Gobiidae sp. B & & & 1 & & & 1 & & & & & & & & & & & & & 2 \\
\hline Gobiidae sp. C & & & & & & & & & & & 1 & & & & & & & & 1 \\
\hline Gobiodon ceremensis & & & & & 1 & & & & & & & & & & & & & & 1 \\
\hline Gobiodon oculolineatus & & & & & 1 & & & & & & & 3 & & & & & & 5 & 9 \\
\hline Gobiodon quinquestrigatus & & & & & & & & & & & & 2 & & & & & & & 2 \\
\hline Gobiodon rivulatus & & & & & 6 & & & & & & & 1 & & & & & & & 7 \\
\hline Gobiodon unicolor & & & & & 3 & & & & & & & 2 & & & & & & 7 & 12 \\
\hline Istigobius aureus & & & & & & 1 & & & & & & & 1 & & & & & & 2 \\
\hline Istigobius rigilius & 1 & & 2 & & & 1 & & & & & 2 & & & & & & & & 6 \\
\hline Oplopomops atherinoides & & & & & & & & & & & 1 & & & & & 1 & & & 2 \\
\hline Paragobiodon echinocephalus & & & & & & & & & & & & & & & & & & 1 & 1 \\
\hline Phyllogobius platycephalops & & & & & & & & & & & 49 & & & & & & 55 & & 104 \\
\hline
\end{tabular}


Appendix 1. (continued)

\begin{tabular}{|c|c|c|c|c|c|c|c|c|c|c|c|c|}
\hline \multirow{2}{*}{$\begin{array}{l}\text { Family } \\
\text { Species }\end{array}$} & \multicolumn{3}{|c|}{${ }_{\text {Reef flat }}$} & \multicolumn{4}{|c|}{ Bommie } & \multicolumn{4}{|c|}{${ }_{-}$Seagrass } & \multirow[t]{2}{*}{ Total } \\
\hline & Por & Rck & Snd Sft Tbl & Por & Rck & Rub Snd Sft & Spg Tbl & Rck & Rub & Snd Sft & Spg Tbl & \\
\hline Pleurosicya cf. boldinghi & & & 3 & & & & & & & 5 & & 8 \\
\hline Pleurosicya muscarum & & & 6 & & & 4 & & & & 8 & & 18 \\
\hline Priolepis nuchifasciata & & & & & & & & & & 1 & 1 & 2 \\
\hline Trimma okinawae & & & & & 1 & & & & & & & 1 \\
\hline Mueranidae & & 2 & & & 1 & & & & 1 & & & 4 \\
\hline Moringua sp. A & & 2 & & & 1 & & & & 1 & & & 4 \\
\hline Pinguipedidae & & & & & & & & 1 & & 1 & & 2 \\
\hline Parapercis synderi & & & & & & & & 1 & & 1 & & 2 \\
\hline Plesiopidae & & 1 & & & & & & & & & & 1 \\
\hline Plesiops coeruleolineatus & & 1 & & & & & & & & & & 1 \\
\hline Pseudochromidae & 5 & 1 & & 7 & 5 & 2 & & 3 & & & 1 & 24 \\
\hline Pseudochromis fuscus & & & & 1 & 2 & & & 3 & & & 1 & 7 \\
\hline Pseudochromis marshallensis & 5 & 1 & & 1 & 1 & 2 & & & & & & 10 \\
\hline \multicolumn{13}{|l|}{ Serranidae } \\
\hline Pseudogramma polyacanthus & & & & 5 & 2 & & & & & & & 7 \\
\hline Scorpaeinidae & 2 & & & & 1 & & & 1 & 2 & & & 6 \\
\hline Scorpaena sp. A & 2 & & & & 1 & & & 1 & 2 & & & 6 \\
\hline Synodontidae & & & & & & & & & & 1 & & 1 \\
\hline Synodus binotatus & & & & & & & & & & 1 & & 1 \\
\hline Tripterygiidae & & & & & & 2 & & 9 & & 1 & 1 & 13 \\
\hline Enneapterygius tutuilae & & & & & & 2 & & 9 & & 1 & 1 & 13 \\
\hline
\end{tabular}

Editorial responsibility: Sean Connell, Adelaide, Australia
Submitted: November 22, 2011; Accepted: May 3, 2012

Proofs received from author(s): June 20, 2012 